Chapman University

Chapman University Digital Commons

3-8-2021

\title{
When Peril Responds to Plague: Predatory Journal Engagement with COVID-19
}

Ryan M. Allen

Follow this and additional works at: https://digitalcommons.chapman.edu/education_articles

Part of the Other Education Commons, Scholarly Communication Commons, and the Social and Philosophical Foundations of Education Commons 


\section{When Peril Responds to Plague: Predatory Journal Engagement with COVID-19}

\section{Comments}

This is a pre-copy-editing, author-produced PDF of an article accepted for publication in Library Hi Tech, volume 39, issue 3 , in 2021 following peer review. The definitive publisher-authenticated version is available online at https://doi.org/10.1108/LHT-01-2021-0011.

This scholarship is part of the Chapman University COVID-19 Archives.

\section{Copyright}

Emerald Publishing Limited 
When Peril Responds to Plague: Predatory Journal Engagement with COVID-19

\begin{tabular}{|r|l|}
\hline Journal: & Library Hi Tech \\
\hline Manuscript ID & LHT-01-2021-0011 \\
\hline Manuscript Type: & Original Article \\
\hline Keywords: & Global, Predatory Journals, Digitization, COVID-19, Publishing, Health \\
\hline
\end{tabular}

\section{SCHOLARONE ${ }^{m}$ \\ Manuscripts}

\section{pre-print}

Citation: Allen, R. M. (2021). When peril responds to plague: predatory journal engagement with COVID-19. Library Hi Tech, 39 (3), 746-760. 


\section{When Peril Responds to Plague: Predatory Journal Engagement with COVID-19}




\section{Introduction}

As researchers around the world scrambled to understand the SARS-CoV-2 (COVID-19) virus in 2020, scholars warned that predatory publishers would attempt to capitalize on the immense need for research related to the pandemic (Memon \& Rathore, 2020; Teixeira da Silva, 2020; Rzymski et al., 2020). Academia has been battling predatory journals long before the arrival of COVID-19. Beninger, Beall, and Shumway (2016) described predatory publishing as a "peril" built on the exploitation of norms within the "scientific publishing community" (p. 4). More concerning given the current health and medical implications, studies written for predatory outlets have been used in the past to support claims made by the anti-vaccination movement (Readfearn, 2018; Bucceri et al., 2019). For instance, Beall (2018) notes that one of the most influential scholars within the anti-vaccine movement has published "unscientific" work in suspected predatory journals as evidence to show the relationship between vaccines and autism (p. 296). Misinformation could further be fueled by articles on COVID-19 that have found homes in predatory outlets with little or no peer review (Vervoort et al., 2020). There is already a torrent of unfounded claims on social media, such as masks reduce oxygen levels or 5G spread the coronavirus, which are conspiracy theories that only threaten public health (Scheirer, 2020; Wani et al., 2021; Warner et al., 2021).

Given the critical need, outlets have attempted to fast-track COVID-19 research that has led to some articles being published before they were ready. In a systematic review of COVID studies, Jung et al. (2020) found that journals peer-reviewed manuscripts on this topic were published more rapidly and with lower methodological standards (it should be noted that this study is still in preprint). Dinis-Oliveira (2020) warned that the rapid push to publish during the pandemic is "speed science" (p. 7), illustrating how the fast-tracking likely led to the use of 
hydroxychloroquine in treating patients with the virus without the standard evidence. While the credible, legitimate publishing space can make mistakes, these are typically amended through corrections or retractions. However, with little editorial standards and some without any genuine peer review (Memon, 2018; Grudniewicz et al., 2019), predatory publishing does not hold to the same corrective mechanism and has the capacity to publish quickly with little recourse, with an average of roughly 50 articles per year (Shen \& Björk, 2015). Despite findings that predatory journal articles often receive few to no citations (Brainard, 2020), the demand for pandemicrelated information could lead to increased usage of lower-quality work compared to normal circumstances (Dinis-Oliveira, 2020; Scheirer, 2020).

The information in predatory journals has already offered a credible threat to academia, but these challenges have only been heightened during the rush for research on the virus and the resulting uncertainties stemming from the pandemic. Academic journals have warned in editorials that predatory publishers might take advantage of the pandemic by putting out virusrelated work (Memon \& Rathore, 2020; Teixeira da Silva, 2020; Rzymski et al., 2020). Given the importance of medical research to the epidemic, there is a heightened urgency surrounding any research focusing on virology, immunology, and epidemiology, which could open vulnerabilities to predatory publishers in these spaces. Indeed, an editorial from Rzymski et al. (2020) in International Immunopharmacology warned of the COVID situation, "There may be 'predatory journals', but there are also 'predatory authors' who are capitalizing on the emergence of a new disease for self-gain" (p. 1). With the recency and ongoing nature of the epidemic, there has been little empirical research on predatory journals and COVID-19 (Vervoort et al., 2020). This research seeks to fill these concerns with an exploration of the publishing practices of 
predatory journals on COVID-19, with a keen focus on the crucial areas of virology, immunology, and epidemiology. This study poses three research questions:

1) How many predatory journals explicitly focus on virology, immunology, and epidemiology and to what degree are their predatory behaviors?

2) What engagement have these predatory journals related to virology, immunology, and epidemiology had with the COVID-19 pandemic research?

3) Uncovered through the exploration of the first two questions, what are the characteristics of the other predatory journals that have published on COVID-19?

\section{Background on Predatory Journals}

While a relatively recent phenomenon in academia, predatory publishing has inundated sectors and fields across the world. In an editorial in the Journal of Epidemiology, Wager (2017) argued, "Rather than viewing predatory publishers as a disease in themselves, I suggest we should regard them instead as a symptom of malaise within the academic research establishment (p. 87)." In this way, the system incentivizes quantity over quality. With these growing pressures to publish, research on the phenomenon has found that some scholars choose these low-quality outlets simply to add an item to their $\mathrm{CV}$, willfully ignoring the detriments to the academy (Demir, 2018; Cobey et al., 2019). Predatory publishers oblige the thirst for publications by offering quick turnaround times on submissions that are not realistic within the standard peerreview process, as long as the author pays the publication fee. Conversely, other scholars simply have had little training or awareness on the topic of predatory publishers. These novice scholars can be confused by the false claims of index inclusion, legitimate-sounding title names, or 
flattering email solicitations (Demir, 2018; Grgić \& Guskić, 2019). Despite the root causes of the problem, predatory journals can now be found in every field and sector across the world.

Much of the concentration of predatory publications has been on less affluent and nonWestern nations, especially in India. Scholars have found that India and other South Asian neighbors account for most of the predatory publishing activity within respective fields (Shen \& Björk, 2015; Kozak, 2016; Moher et al. 2017; Petrisor, 2019). But the geographic impact of these types of publishers still reaches beyond the subcontinent, especially in other developing academic sectors like in the Middle East (Shehata \& Elgllab, 2018) and to Sub-Saharan Africa (Shen \& Björk, 2015). In general, predatory journals take advantage of non-native Englishspeaking academics, as pressures for international English language journals have become commonplace globally $\left(\mathrm{O}^{\prime} \mathrm{Neil}, 2018\right)$. However, the problem is truly global, as research has found predatory journal articles from scholars located in affluent systems in Europe (Strielkowski et al., 2017; Grgić \& Guskić, 2019) and in the United States (Moher et al., 2017). Predatory publishers indiscriminately flood inboxes across the world and the practice has become boundless across disciplines.

Despite the various reasons some scholars may publish in them or the geography epicenter for predatory publishing, the phenomenon has left a conundrum for libraries dealing with digitization and new open access outlets (Hey \& Hey, 2006; Beall, 2016a; Grudniewicz et al., 2019). Science had been long guarded through limited availability and paywalls, but open access has had the dueling effect of democratizing research while providing space for predatory journals to thrive (see Kusekwa \& Mushowani, 2014; Dandawate \& M, 2019). For instance, the style of Gold Open Access has authors pay publishing fees before publication, a change that removes paywalls and gives access to the knowledge produced to anyone across the world. Legitimate 
Gold Open Access journals like PLOS ONE have been on the forefront of expanding scientific access, but most predatory publishers also claim to be part of the open access movement, asking potential victims to pay fees, often without real peer review or other oversights (Masten \& Ashcraft, 2016; Ghanbari et al., 2019). Because predatory publishers have latched onto the wave of open access, identifying predatory journals has proven quite complicated.

\subsection{Blacklists/ Whitelists}

There is no one simple metric to identify predatory journals. In 2019, the editors of Nature organized a global discussion of 43 academics, funders, publishers, and other sector leaders to create agreed-upon markers to identify predatory journals, but during a 12-hour discussion they admitted that consensus was challenging due to differing perceptions and expectations (Grudniewicz et al, 2019). In the end, they established the following standards of identification: "False or misleading information," "Deviation from best editorial and publication practices," "Lack of transparency," and "Aggressive, indiscriminate solicitation" (Grudniewicz et al., 2019, p. 211-212). One key issue that was discussed was the use of blacklists to identify predatory publishers or journals and whitelists for legitimate counterparts. While it is recognized that no list can be foolproof, various indices have become widely used tools for academics in recognizing and understanding the academic publishing space (Berger \& Cirasella, 2015; Teixeira da Silva \& Tsigaris, 2018). For instance, indices such as Science Citation Index (SCI) or Scopus have provided a status maker beyond legitimacy, as there is a perceived elite status for those titles that have been included (Chou, 2014; Author, 2019). Given these gatekeeping functions, predatory journals often falsely claim inclusion in various indices that are viewed as kinds of whitelists (Masten \& Ashcraft, 2016). While predatory journals have sometimes popped 
up on these indices or have been hijacked by predatory practitioners, the organizations consistently curate their listings to maintain legitimacy (Grudniewicz et al., 2019). Jeffery Beall, a librarian at the University of Colorado, first brought attention to the topic of predatory journals by starting a small warning blog of dubious publications in 2008 that evolved into a larger, widely-used blacklist until 2017. However, Beall and his institution were threatened with legal action over his predatory blacklisting and criticized for lack of transparency in the process (Teixeira da Silva \& Tsigaris, 2018; Buschman, 2020). There were also critiques that his list mostly included publishers in non-Western societies, adding disagreement about who has the right to create knowledge and hegemonic practices (Ebadi \& Zamani, 2018). With these difficulties, especially from the legal aspect, resulted in Beall giving up his website and list. In a eulogy editorial, Watson (2017) proclaimed, "In my view, a valuable service has died and gone; will some Phoenix 'arise from the ashes?' (p. 60).” In subsequent years, though, anonymous advocates of the mission have taken on the call and continued Beall's List, building and adding to the original list. The new list is still widely used, as it is one of the most famous, free blacklists of predatory journals among others that have arisen since the closing of the original.

Given that predatory publishers have attempted to ride the wave of open access, the Directory of Open Access Journals (DOAJ) was launched in 2003 in an attempt to protect the integrity of the movement through a public whitelist, organized through a collaborative community effort from Lund University, Open Society Institute, and The Scholarly Publishing and Academic Resources Coalition (Trencheva \& Todorova, 2014). The DOAJ provides standards and practices for listed journals — curating, adding, or removing various titles to maintain quality. In 2013, due to concerns of predatory publishing and lapses in standards (Bohannon, 2013), the DOAJ updated its inclusion criteria, strengthening efforts such as 
archiving, copywriting, and transparent peer review policies, and forced journals to reapply for listing (Richtig et al., 2018). While the changes resulted in a purge of over 3700 journals, there have still been mixed receptions of initiative's efficacy (Marchitelli et al, 2017; Teixeira da Silva et al., 2018). For instance, illustrating that no whitelist is perfect, Sorokowski et al. (2017) conducted a sting operation to explore if journals accepted a fake editor application for board membership, resulting in several DOAJ titles offering the fictitious editor a position. According to the DOAJ website, the organization maintains that the majority of its listed 15,679 journals meet a high standard and inclusion is consistently interrogated.

While Beall sounded the alarm bells with his list and the DOAJ has been the de facto openaccess whitelist, Cabells, a for-profit firm, has stepped up to offer services in determining the legitimacy of journals and publishers, among other academic offerings. In 2017, Cabells created a new listing for predatory journals called "Predatory Reports" and legitimate publications called "Journalytics" that take note of the critiques levied against Beall's List by adding transparency and violation reports (Bisaccio, 2018). Rather than simply labeling journals and publishers as predatory or not, the company established a set of predacious behaviors that could be checked, verified, or appealed, providing a spectrum of what it means to be predatory (Hoffecker, 2018). The process allows for journals to be removed and upgraded (or downgraded) from the lists and, by 2020 , the blacklist included over 13,500 journal titles. Due to the intensity and work involved in chronicling the entire academic publishing sector, the company only offers its service to paying customers, often through institutional subscriptions. Nonetheless, it is one of the most comprehensive listings of predatory journals, well beyond that of Beall's List (Chen, 2019), but critiques remain for the service's efficacy (Teixeira da Silva \& Tsigaris, 2018). 


\section{Methodology}

This research set out to explore the publishing practices of predatory journals on COVID-19, with a keen focus on the fields most critical to understanding and controlling the pandemic. Using the Cabells' Predatory Reports list in July 2020, the first sample was built through a search for journal titles that included the following words or variants: virology, immunology, or epidemiology. The sample included 162 journals related to these terms. All of these publications were labeled as "Medicine" or "Biological Sciences, Medicine" by Cabells. Next, the Cabells' Predatory Report for each of the virology, immunology, or epidemiology titles was tallied. For this research, the number of violations and the broad violation type has been included to understand the spectrum of predatory behaviors. Cabells records violations for the following categories: Integrity, Peer Review, Publication Practices, Fees, Indexing \& Metrics, Access \& Copyright, and Business Practices. Each of these categories is rated as severe, moderate, or minor by the firm and tallied in this research for the samples. A detailed description of the behaviors and the spectrum can be found in the online supplement.

To operationalize the content analysis (see Neuendorf, 2012), each of the journals' websites was coded for information pertinent to understanding engagement with the pandemic. The first code was whether COVID-19 (or any variant such as Coronavirus) was found on the front landing page for the journal. Next, it was recorded if the journal had published any articles in 2020 and if any of the 2020 publications were focused on the virus. The websites were also coded for Call for Papers (CfP) or Special Issues related to the pandemic, warnings related to slow peer review due to COVID, and any other COVID-related items (such as a COVID-19 tracker). The codebook for the content analysis can be found in the online supplement. A first 
pass of the website coding collection was done in July 2020, followed by a second pass in December 2020 to capture the entire year.

To provide a comparison group for journals that have not displayed predatory behaviors, a sample of journals was also taken from the DOAJ, with an inclusion criteria of any virology, immunology, or epidemiology journal in the database and that was in English. This DOAJ comparison sample included 251 journals. In parallel to the first sample, each journal website was coded and the titles were cross-referenced through both Cabells' Predatory Report and Journalytics - none were found on the predatory list and 28 were found on the whitelist. To determine significance beyond a practical difference, Pearson's chi-squared tests were used to compare the content analysis results between the Cabells' Predatory Report virology, immunology, or epidemiology journals and the DOAJ peers, in accordance to similar content analyses studying journal publications (see Tsai \& Lydia Wen, 2004; Lin et al., 2014; and Lee 2017).

In order to broaden the limited scope of the first sample that only relied upon virology, immunology, or epidemiology, another predatory sample was collected to provide a fuller picture of the predatory publishing landscape on COVID-19. Using the websites' search functions and Google's "site:website" search tool during the initial content analysis, any connected journals from the same publisher that had articles CfP related to the pandemic were recorded and added to a second suspected predatory sample. A total of 329 publications were found through the initial search and were organized for analysis. This new sample was cross-referenced with Cabells' Predatory Report, Cabells' Journalytics, and the DOAJ. If they were within the Predatory Report, the number of violations was reported along with the academic field. None of these publications were found on the Journalytics whitelist nor on the DOAJ. 


\section{Empirical Findings}

\subsection{Virology, Immunology, or Epidemiology-Focused Predatory Journals}

In total, there were 162 journals directly related to virology, immunology, or epidemiology found on Cabells' Predatory Report list, meaning that these entries had at least one predatory practice out of the established list of violations from the organization. They came from 33 different publishers. Displayed in Table 1 and in conjunction with the first research question, overall, there were 1,032 infractions found by Cabells' auditors for this specific set of journals, with an average of 6.37 predatory practice infractions per journal and a standard deviation of roughly two infractions for the virology, immunology, or epidemiology sample. For this specific dataset, only a few journals had 10 or more infractions, while none had three or below. The Cabells' service, unfortunately, does not provide an average for the entire database to make a comparison. But even just one severe infraction can be understood as a critical loss of a journal's credibility, garnering apprehension for the science it publishes.

Table 1: Virology, Immunology, or Epidemiology Journal Cabells' Predatory Report Summarization Full Sample

\begin{tabular}{lllll}
\hline & All Infractions & Severe & Moderate & Minor \\
\hline Total & 1032 & 291 & 439 & 302 \\
Mean & 6.37 & 1.80 & 2.71 & 1.86 \\
SD & 2.02 & 0.998 & 1.33 & 1.25 \\
\hline
\end{tabular}

Source: Compiled by the author from Cabells' Predatory Report.

The level of infractions is useful for gauging the spectrum of predacious behaviors these journals exhibit and is a key advantage of using this kind of reporting mechanism rather than simple blacklists. The severe infractions are the most egregious on the Predatory Report that includes critical threats to the integrity of academic research such as no peer review or lying about inclusion on indices (see the online supplement for more details). There were a total of 291 severe infractions, with a mean of 1.80 severe infractions per journal and a standard deviation of 
roughly one. Moderate infractions still pose concerns for academic integrity but are deemed less threatening overall, such as obscuring for-profit nature or suspicious focus on fees. These midlevel infractions accounted for the most violations within these virology, immunology, or epidemiology journals for a total of 439 for the sample, with a mean of 2.71 per outlet and a standard deviation of 1.33. Finally, minor infractions, while certainly an issue for the academic community, do not pose a serious threat to academic findings - these include items like a lack of editing or website problems. There was a total of 302 minor infractions, averaging 1.86 per journal in the sample, with a standard deviation of 1.25 .

\subsection{Website Content Analysis}

Stemming from the exploration of research question two, the front home page for each journal website was coded for any mention of COVID-19 (or its variants), with the results shown in Table 2. Of the 162 journals established from the Cabells' Predatory Report list, just over 67\% had no publishing activity in 2020. A large swath of the sampled titles appeared to be completely defunct, with journal publishers squatting on the names, as only 53 had published any articles during the year. Some of these publishers displayed no activity across all of their connected journals or websites, but others were newly defunct. Despite this barren finding, there was still activity related to COVID-19 in this virology, immunology, or epidemiology sample. Overall, 41 journals had some type of material related to the pandemic on the front landing page, which was only $25.31 \%$ of the sample. Although, $77.36 \%$ of the active journals (e.g. those that had published in 2020) had COVID-19 related material on the journal landing page, which was often related to a publication (sometimes from a different title of the same publisher). 
In terms of active research, only 39 of the journals had published an article related to COVID-19 in 2020. This means that almost a quarter of the sample published research related to the pandemic during the year, which accounted for $73.58 \%$ of all active publications in the sample. Relatedly, there were only five total Calls for Papers related to the topic of the virus in this sample. There were also only five warnings concerning slower peer review processes related to the effects of the pandemic on reviewers, editors, or journal operations, which all came from journals under the same publisher. There were 21 instances of other pandemic material found on the websites, usually an infection tracker or linked social media posts from the journal or publisher.

Table 2: Content Analysis Results of Predatory Virology, Immunology, or Epidemiology Journal Websites

\begin{tabular}{llllllll}
\hline Element: & $\begin{array}{l}\text { Active in } \\
\text { 2020 }\end{array}$ & Front Page & $\begin{array}{l}\text { Call for } \\
\text { Papers }\end{array}$ & $\begin{array}{l}\text { Slow } \\
\text { Warning }\end{array}$ & $\begin{array}{l}\text { Publication } \\
\text { on COVID }\end{array}$ & Other & Publishers \\
\hline Total & 53 & 41 & 5 & 5 & 39 & 21 & 33 \\
\% of All & $32.72 \%$ & $25.31 \%$ & $3.09 \%$ & $3.09 \%$ & $24.07 \%$ & $12.96 \%$ & - \\
\% of Active & - & $77.36 \%$ & $9.43 \%$ & $9.43 \%$ & $73.58 \%$ & $39.62 \%$ & - \\
\hline
\end{tabular}

Source: Collected and coded by the author from the journals' websites.

Comparing the content analysis findings of the DOAJ sample journals to the Cabells' Predatory Report list yielded differences in behaviors, with the DOAJ descriptive statistics displayed in Table 3. Most $(95.62 \%)$ of the DOAJ journals were active in 2020, a difference in frequency that was statistically significant through the chi-square test when compared to the predatory sample $(\chi 2=188.98, \mathrm{p}<.001)$. While roughly half of the DOAJ journals had some kind of COVID-19 material listed on their website landing pages, around three quarters had published research on the virus in 2020 and around 12\% had special issues or call for papers on the pandemic, all of which were statistically significant differences from the Cabells' listed journals $\left(\chi^{2}=25.33, \mathrm{p}<.001 ; \chi^{2}=104.47, \mathrm{p}<.001\right)$. One key difference between the DOAJ listed journals and those on the Predatory Report was that roughly $30 \%$ of the legitimate titles listed some kind of warning or commentary related to the impact of the pandemic on the peer 
review process, a statistically significant result $(\chi 2=44.34, \mathrm{p}<.001)$. One comparison that was not statistically different from the predatory sample was that only around $10 \%$ of the DOAJ journals included other material related to COVID-19 on their websites, often a Twitter feed $(\chi 2$ $=1.17, \mathrm{p}>0.05)$. Finally, these comparison journals came from 115 different publishers, some larger and well known, but others smaller like those from individual universities or societies.

Table 3: Content Analysis Results of the DOAJ Virology, Immunology, or Epidemiology Journal Websites

\begin{tabular}{llllllll}
\hline Element: & $\begin{array}{l}\text { Active in } \\
\text { 2020 }\end{array}$ & Front Page & $\begin{array}{l}\text { Call for } \\
\text { Papers }\end{array}$ & $\begin{array}{l}\text { Slow } \\
\text { Warning }\end{array}$ & $\begin{array}{l}\text { Publication } \\
\text { on COVID }\end{array}$ & Other & Publishers \\
\hline Total & 240 & 126 & 31 & 74 & 189 & 24 & 115 \\
\% of All & $95.62 \%$ & $50.20 \%$ & $12.35 \%$ & $29.48 \%$ & $75.30 \%$ & $9.56 \%$ & - \\
\% of Active & - & $52.50 \%$ & $12.91 \%$ & $30.83 \%$ & $78.75 \%$ & $10.00 \%$ & - \\
\hline
\end{tabular}

Source: Collected and coded by the author from the journals' websites.

It could be reasonable to wonder if the 39 suspected predatory journals that published on COVID-19 might have had better records than the inactive peers in the sample, given that predatory behaviors can be considered as a spectrum, and a better comparison for the DOAJ journals. Indeed, the chi-square tests comparing only those journals active in 2020 did yield some differing results. In comparison to only active journals, the codes of COVID-19 on the landing page $(\chi 2=2.38)$, special issues on the pandemic $(\chi 2=0.48)$, and publications on the topic $(\chi 2=1.77)$ yielded no statistical differences in the tests (all with $p>0.05)$. Conversely, there was a difference in terms of other materials related to COVID-19 on the websites $(\chi 2=$ $17.58, \mathrm{p}<0.001)$. But the most telling code of a warning issued related to peer review slowdowns due to the pandemic remained present in both comparisons. There was a 20-percentage point difference in frequency of reporting peer review slowdowns in favor of DOAJ $(30.83 \%)$ compared to those active Predatory Report journals (9.43\%), statistically different in the test $(\chi 2$ $=10.10, \mathrm{p}<0.01)$. 
While five of the active suspected predatory journals did include a warning of possible disruption of peer review due to the pandemic, the overall grouping of this active group's Cabells' reports did not appear that much different from the rest of the sample. Illustrated in Table 4, these outlets that published on COVID-19 averaged 1.41 severe infractions and 1.48 minor infractions, both types registering slightly below the mean of the entire sample. However, these 39 publications also account for an average of 3.21 moderate infractions, slightly above the mean. These journals that published on the pandemic, though, had larger standard deviations of the severe and moderate infractions compared to the rest of the sampled publications, indicating more variation in these active predatory journals.

Table 4: Summary of Cabells' Predatory Report for Virology, Immunology, or Epidemiology Journal That Published on COVID-19 in 2020

\begin{tabular}{lllll}
\hline & All Infractions & Severe & Moderate & Minor \\
\hline Total & 238 & 55 & 125 & 58 \\
Mean & 6.10 & 1.41 & 3.21 & 1.48 \\
SD & 2.07 & 1.21 & 1.52 & 1.01 \\
\hline
\end{tabular}

Source: Compiled by the author from Cabells' Predatory Report.

\subsection{Discovered Journals}

Beyond the virology, immunology, or epidemiology specific Predatory Report journals, the broader predatory publisher ecosystem was also a crucial aspect in this exploration, corresponding with the third research question. Of the sample, there were a total of 33 publishers that had other journals engaging with material related to the pandemic, which each house a stable of journals in various fields or sectors. With the website search described in the methodology, a total of 329 journals were discovered that had published on or issued a CfP related to COVID19. Of these titles, 284 were found to have infractions on Cabells' Predatory Report. These publications had a mean of 6.48 infractions per journal, with a standard deviation of 1.8 . The descriptive characteristics in the second sample of journals were comparable to the first sample's overall infraction numbers. Of the titles there were not found on the Predatory Report, none 
appeared on Cabells' Journalytics whitelist. Thus, it cannot be determined if these publications are predatory or legitimate.

Chart 1: Medical or Bio.-Related Journals Listed on Cabells Predatory Report That Published on COVID-19

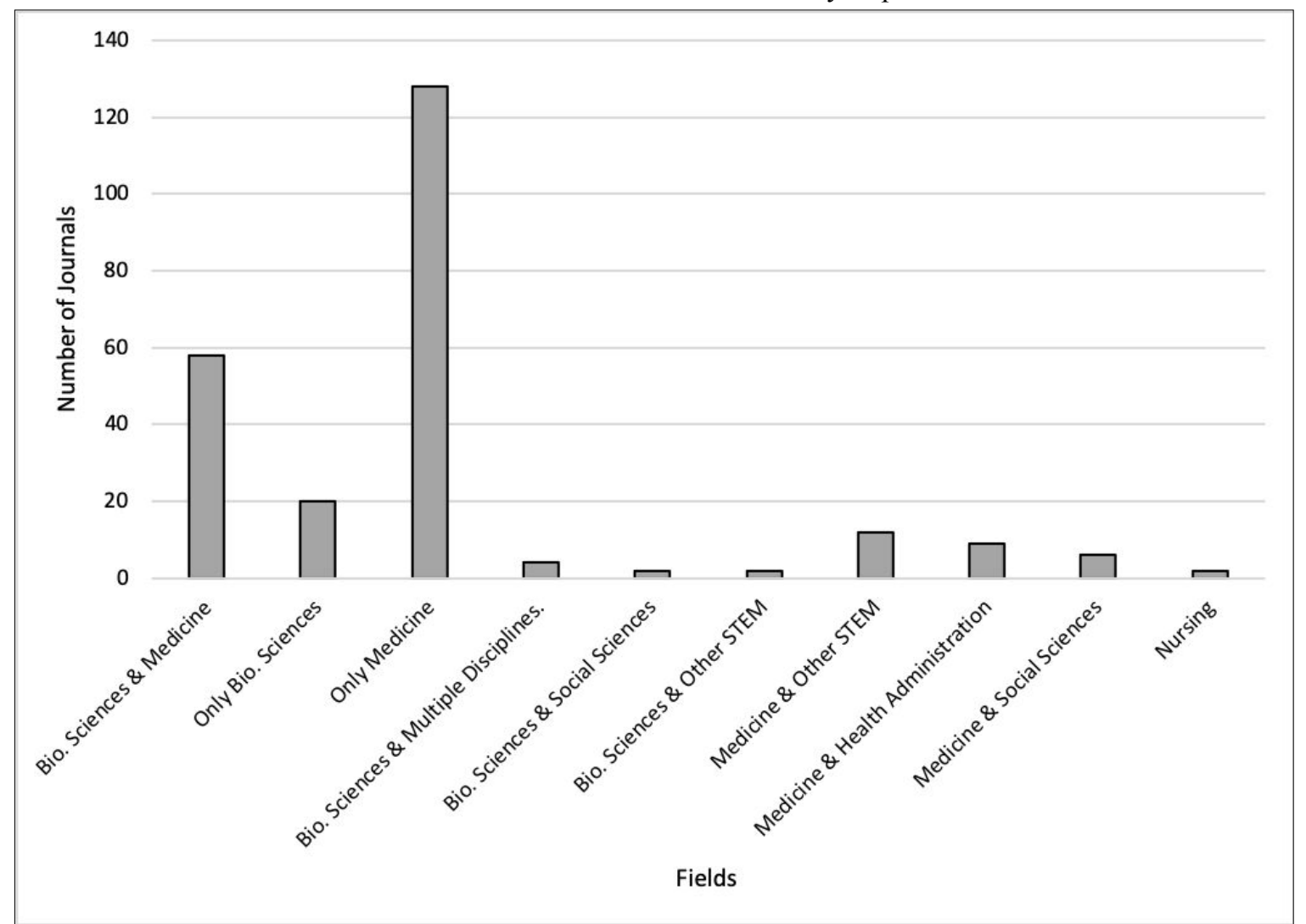

Source: Compiled by the author from Cabells' Predatory Report.

Similar to the initial set of journals in the first sample, most of the titles in the discovered sample were also categorized as "medicine" related publications, accounting for 243 journals that spanned multiple subfields in this categorization, illustrated on Chart 1 . The majority of these were labeled as only medicine (127), biological sciences \& medicine (58), or only biological sciences (20). There were also some listings from other biological or medical-related fields, such as medicine \& other STEM fields (12), medicine \& health administration (9), medicine \& social sciences (6), biological sciences \& multiple disciplines (4), biological sciences \& social sciences (2), biological sciences \& other STEM fields (2), and nursing (2). The strong 
centering on these specific types of journals illustrates the specific threat to biological sciences and medical publishing as warned by scholars such as Beall (2016), Watson (2017), and Bucceri et al. (2019).

Chart 2: Journals From Other Fields Listed on Cabells Predatory Report That Published on COVID-19

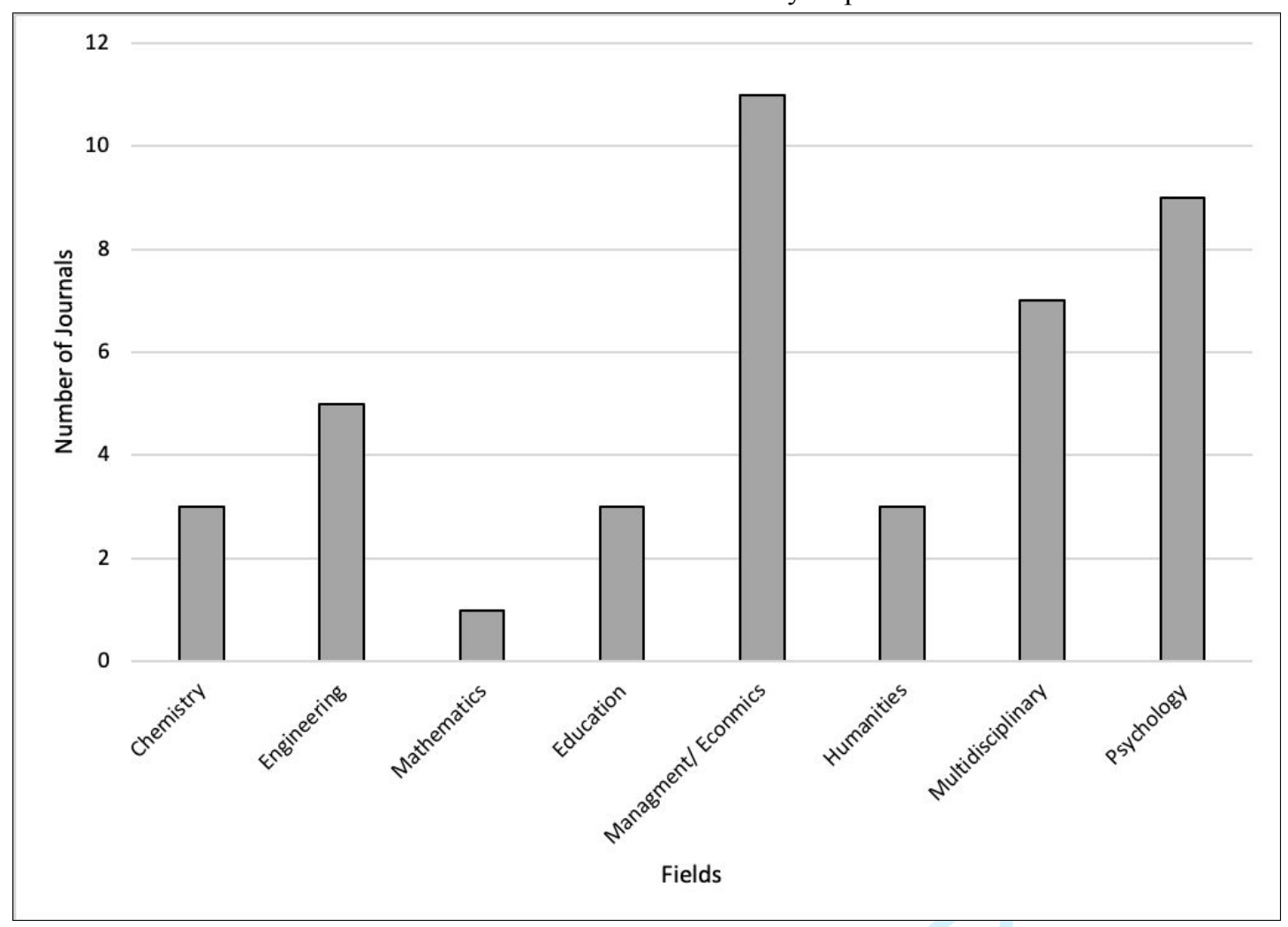

Source: Compiled by the author from Cabells' Predatory Report.

Unlike the initial journal list, the outlets discovered in this sample go beyond the virology, immunology, and epidemiology topics that center on medical or biological science fields. In this uncovered set of journals with engagement on the pandemic, there were 42 titles listed in eight different fields, including economics or management (11), psychology (9), multidisciplinary (7), engineering (5), chemistry (3), mathematics (1), education (3), and humanities (3). While these fields encompass other natural sciences, social sciences, and humanities, it was somewhat surprising to find so few of these publications engaging with COVID-19 related material as 
compared to the medical or bioscience sample. Only the economics or management category was found to have double-digit publications of these other fields. Although, there could be some crossover from the medical and biology multidisciplinary journals, too. Nonetheless, these findings show that there is at least some engagement with COVID-19 from a broad range of fields, but with a specific concern for health and medical areas.

\section{Discussion and Conclusion}

\subsection{Discussion}

At the height of the COVID-19 pandemic, various members within the academic community issued warnings against the possibility that predatory journals could prey on the uncertainties of the situation, especially with health-related research (see Memon \& Rathore, 2020; Teixeira da Silva, 2020; Rzymski et al., 2020). With the findings in this research, many of the journals in the sample were defunct, but there were still hundreds of active journals with predatory practices engaging with pandemic-related studies (39 from the virology sample and 284 from the discovered sample), which were largely centered around medical or biological publications. While any predatory publishing presents a peril to legitimacy for academia, false information in the medical and health professions can directly lead to harm or death (Beall, 2016a). Even in small quantities, predatory publishers can spread misinformation, especially with growing concerns of research literacy and social media networks (see Beall, 2018; Readfearn, 2018; Bucceri et al., 2019; Wani et al., 2021; Warner et al., 2021).

One somewhat surprising finding was that there were not more journals discovered from other fields publishing on the pandemic (only 42 total). This could indicate that these predatory publishers could specifically specialize in medical/ biological science fields. Although, the 
finding offers some pushback against the notion that these types of publishers have wide as possible scopes for the potential to lure more victims (Beall, 2013). Research should look beyond these medical-related fields in an expansion to understand humanities and other social sciences with regard to predatory publishing. While the medical fields have especially taken predatory journals seriously with open editorials and other warnings, some fields have not put much focus on the phenomenon (Author Redacted). Potentially, predatory publishers simply are not operating at nearly the same level as with some of the more well-documented fields like medicine.

The results of the comparison between the DOAJ journals and those suspected to be predatory were telling. While much of the journals found on Cabells' Predatory Report were defunct, there were still many that were active in 2020 participating in the discourse on COVID19. In this study, the DOAJ journals were more likely to issue warnings or notes on the slowdown or problems with the peer review, but still roughly $70 \%$ of these publications had no message of this kind on the website, connecting with the concerns of "speed science" (DinisOliveira, 2020). Scholars such as Teixeira da Silva and Tsigaris (2018) and Grudniewicz et al. (2019) have warned of simply relying on one list to make determinations of predatory status, such as DOAJ inclusion. When cross-referencing the various lists used in this research, none of the DOAJ journals were found to be on Cabells' Predatory Report and 28 of them were even listed on the agency's Journalytics list of top journals. Likewise, none of the suspected predatory journals could be found on the DOAJ. Broadly, DOAJ's curation of acceptable practices and standards should be a positive sign for the understanding predatory phenomenon. While Cabells provides a useful service for active curation and spectrums of suspected predatory behaviors, it requires a subscription that likely precludes those without institutional resources. Meanwhile, the 
usage of DOAJ is a free service available to anyone with internet access. Even with its own critiques (Marchitelli et al., 2017; Sorokowski et al., 2017), the DOAJ will be an invaluable public utility for research literacy and the legitimacy of the open access movement, especially given the medical falsehoods and misinformation that have spread in recent years.

\subsection{Conclusion}

As science has moved from behind paywalls and online through digitization, the general public now has greater access to studies and research. But given that scholars and graduate students have been duped by predatory journals (Demir, 2018; Grgić \& Guskić, 2019), those without specific training in advanced research or information literacy skills may have even more problems. Likewise, universities have specially trained librarians and information technology staff to curate and vet their collections, services that only become more crucial during crises (Guo et al., 2020). Even if predatory publications get few academic citations, Beall (2016b; 2018) argues that political activists and other stakeholders have misused results in them as evidence for their positions, like in the case of anti-vaccinations campaigns. These complexities surrounding academic publishing could create even more confusion and misinformation, especially in the medical and health fields where distortion can mean life or death. It is no wonder that these health fields have paid close attention to the potential damage caused by predatory journals with editorials and guidelines warning about the phenomenon in editorials or other public science communication (see Wager, 2017; Bucceri et al., 2019; Rzymski et al., 2020). During the age of COVID, this potential and specific threat to the integrity of health and medical research is cause for alarm. Libraries and the broader educational community may have 
an obligation to help comb through potential peril within the open access movement for public consumption.

This study does not prove that predatory publications have released misinformation pertaining to COVID-19, but rather it illustrates the potential within a complex academic publishing space. Researchers must continue to explore engagement with predatory publishing, especially in terms of monitoring the content of virus-related work. Even as predatory journals do not receive many (or any) citations (Brainard, 2020), the emergency nature of the pandemic and rapid push for so-called "speed science" on the pandemic could result in any pieces published early to be given undue credibility (Dinis-Oliveira, 2020). These dubious publications without proper peer review could infect the rest of COVID-19 research by gaining citations or spreading across social media, clouding insight into the pandemic and eroding public trust. Furthermore, the growing pushback by segments of society against masking, anti-vaccines, and other public health issues could seriously harm the global recovery efforts from the pandemic, potentially leading to more deaths and broadening the damage that the lockdowns have had on society. Predatory journals have already proven to be vectors of misleading science that have been used as evidence in movements that have championed dubious science (Readfearn, 2018; Bucceri et al., 2019). With the findings in this study, it appears that there is, at the very least, the potential for misinformation related to COVID-19 stemming from publications with predatory practices.

\subsection{Limitations}


There are limitations to this study that should be noted. First, this study did not gauge the content within these predatory journals, as the evaluation of the studies was not within the scope of the research. The journals that have been found to publish on the virus could potentially publish work that is not damaging to the understanding of its spread, even as the publishers have used predacious tactics. Future research should consider a deeper analysis of COVID-19 studies published within these predatory outlets produced during the pandemic, similar to the work by Jung et al. (2020) on legitimate publications. Likewise, the 742 total journals analyzed in this study represent only a fraction of published research. For instance, PubMed lists over 86,700 articles on COVID-19 as of the date of this study. Comprehensive and longitudinal studies should be implemented in the future to fully grapple with the produced corpus of knowledge on the virus. The findings do, however, illustrate a publishing ecosystem in which harmful information could potentially be published, similar to past work on anti-vaxxers (Beall, 2018; Readfearn, 2018; Bucceri et al., 2019) and akin to comparable research on the pandemic (see Guo et al, 2020).

Second, relying on blacklists poses complications, as some scholars have questioned their reliability (Teixeira da Silva \& Tsigaris, 2018) and others have noted that they do not provide a universal identification (Grudniewicz et al., 2019). Further, the security functions on the Cabells' website, even with an institutional license, limits some of its functionality for use in research. As noted by Hoffecker (2018), it is difficult to analyze the entire database due to missing aspects like sorting by the number of violations or specific fields, disallowing the opportunity to make broader comparisons. Nonetheless, past studies have used blacklists in order to build predatory journal samples (see Shehata \& Elgllab, 2018; Cobey et al., 2019; and Grgić \& Guskić, 2019). 


\begin{abstract}
While the sole use of either blacklists or whitelists is not recommended, they do provide an important indicator for more holistic assessments of journal quality.
\end{abstract}

\title{
References
}

Author Redacted

Beninger, P. G., Beall, J., \& Shumway, S. E. (2016). Debasing the currency of science: The growing menace of predatory open access journals. Journal of Shellfish Research, 35(1), $1-5$.

Berger, M., \& Cirasella, J. (2015). Beyond Beall's list: Better understanding predatory publishers. College \& research libraries news, 76(3), 132-135.

Beall, J. (2013). Avoiding the Peril of Publishing Qualitative Scholarship in Predatory Journals. Journal of Ethnographic \& Qualitative Research, 8(1).

Beall, J. (2016a). Dangerous predatory publishers threaten medical research. Journal of Korean medical science, 31(10), 1511-1513.

Beall, J. (2016b). Essential information about predatory publishers and journals. International Higher Education, (86), 2-3.

Beall J (2018). Scientific soundness and the problem of predatory journals, in: Pseudoscience:

The Conspiracy Against Science, Kaufman A.B. \& Kaufman J.C. (eds.), pp 183-300.

Bisaccio, M. (2018). Cabells' Journal Whitelist and Blacklist: Intelligent data for informed journal evaluations. Learned Publishing, 31(3).

Bohannon J. Who's afraid of peer review. Science. 2013;342:60-5.

Brainard, J. (2020). Articles in 'predatory' journals receive few or no citations. Science. doi:10.1126/science.aba8116 
Bucceri, A., Hornung, P., \& Schindler, T. M. (2019). Predatory publishing-what medical communicators need to know. Medical Writing, 28, 28-33.

Chen, X. (2019). Beall's List and Cabell's Blacklist: A Comparison of Two Lists of Predatory OA Journals. Serials Review, 45(4), 219-226.

Chou, C. P. (Ed.). (2014). The SSCI syndrome in higher education: A local or global phenomenon. Springer Science \& Business Media.

Cobey, K. D., Grudniewicz, A., Lalu, M. M., Rice, D. B., Raffoul, H., \& Moher, D. (2019). Knowledge and motivations of researchers publishing in presumed predatory journals: a survey. BMJ open, 9(3), e026516.

Dandawate, V.S. and M. D. (2019). A review of the open-access scenario in Afghanistan. Library Hi Tech. 37(4), 660-668.

Demir, S. B. (2018). Predatory journals: Who publishes in them and why? Journal of Informetrics, 12(4), 1296-1311.

Dinis-Oliveira, R. J. (2020). COVID-19 research: pandemic versus "paperdemic", integrity, values and risks of the "speed science". Forensic Sciences Research, 1-14.

Ebadi, S., \& Zamani, G. (2018). Predatory publishing as a case of symbolic violence: A critical English for academic purposes approach. Cogent Education, 5(1), 1501889.

Ghanbari Baghestan, A., Khaniki, H., Kalantari, A., Akhtari-Zavare, M., Farahmand, E., Tamam, E., ... \& Danaee, M. (2019). A Crisis in "Open Access": Should Communication Scholarly Outputs Take 77 Years to Become Open Access?. SAGE Open, 9(3), 2158244019871044.

Grgić, I. H., \& Guskić, M. (2019). Croatian scientists' awareness of predatory journals. International Journal for Educational Integrity, 15(1), 3. 
Grudniewicz, A., Moher, D., Cobey, K. D., Bryson, G. L., Cukier, S., Allen, K., ... \& Ciro, J. B. (2019). Predatory journals: no definition, no defence. Nature. 576, 210-212.

Guo, Y., Yang, Z., Yang, Z., Liu, Y. Q., Bielefield, A., \& Tharp, G. (2020). The provision of patron services in Chinese academic libraries responding to the COVID-19 pandemic. Library Hi Tech. EarlyCite.

Hey, T. and Hey, J. (2006), e-Science and its implications for the library community. Library Hi Tech. 24(4), 515-528.

Hoffecker, L. (2018). Cabells scholarly analytics. Journal of the Medical Library Association: JMLA, 106(2), 270.

Jung, R. G., Di Santo, P., Clifford, C., Prosperi-Porta, G., Skanes, S., Hung, A., ... \& Hibbert, B. (2020). Methodological Rigor in COVID-19 Clinical Research: A Systematic Review and Case-Control Analysis. medRxiv.

Kozak, M., Iefremova, O., \& Hartley, J. (2016). Spamming in scholarly publishing: A case study. Journal of the Association for Information Science and Technology, 67(8), 20092015.

Lee, T. H. (2017). The status of corporate social responsibility research in public relations: A content analysis of published articles in eleven scholarly journals from 1980 to 2015. Public Relations Review, 43(1), 211-218.

Lin, T. C., Lin, T. J., \& Tsai, C. C. (2014). Research trends in science education from 2008 to 2012: A systematic content analysis of publications in selected journals. International Journal of Science Education, 36(8), 1346-1372.

Kusekwa, L. and Mushowani, A. (2014). The OA landscape in Zimbabwe: the case of university libraries in ZULC. Library Hi Tech, 32(1), 69-82 
Marchitelli, A., Galimberti, P., Bollini, A., \& Mitchell, D. (2017). Improvement of editorial quality of journals indexed in DOAJ: a data analysis. JLIS. it: Italian Journal of Library, Archives and Information Science. Rivista italiana di biblioteconomia, archivistica e scienza dell'informazione, 8(1), 1-21.

Masten, Y. B., \& Ashcraft, A. S. (2016). The dark side of dissemination: Traditional and open access versus predatory journals. Nursing Education Perspectives, 37(5), 275.

Memon, A. R. (2018). Predatory journals spamming for publications: what should researchers do?. Science and engineering ethics, 24(5), 1617-1639.

Memon, A. R., \& Rathore, F. A. (2020). Publishing research during pandemics: are you vulnerable to the COVID-19 or predatory publishers?. J Pak Med Assoc, 70.

Moher, D., Shamseer, L., Cobey, K. D., Lalu, M. M., Galipeau, J., Avey, M. T., ... \& Daniel, R. (2017). Stop this waste of people, animals and money. Nature News, 549(7670), 23.

Neuendorf, K. (2017). The content analysis guidebook. Los Angeles: SAGE.

Petrisor, A.-I. (2016). Evolving strategies of the predatory journals. Malaysian Journal of Library and Information Science, 21(1), 1-17.

O'Neil, D. (2018). English as the lingua franca of international publishing. World Englishes, 37(2), 146-165.

Readfearn, G. (2018). Murky world of 'science 'journals a new frontier for climate deniers. The Guardian, 28.

Rzymski, P., Nowicki, M., Mullin, G. E., Abraham, A., Rodríguez-Román, E., Petzold, M. B., ... \& Janne, P. (2020). Quantity does not equal quality: Scientific principles cannot be sacrificed. International immunopharmacology, 86, 106711. 
Scheirer, W. (2020). A pandemic of bad science. Bulletin of the Atomic Scientists, 76(4), 175184.

Shehata, A. M. K., \& Elgllab, M. F. M. (2018). Where Arab social science and humanities scholars choose to publish: Falling in the predatory journals trap. Learned Publishing, 31(3), 222-229.

Shen, C., \& Björk, B. C. (2015). 'Predatory' open access: a longitudinal study of article volumes and market characteristics. BMC medicine, 13(1), 230.

Sorokowski, P., Kulczycki, E., Sorokowska, A., \& Pisanski, K. (2017). Predatory journals recruit fake editor. Nature News, 543(7646), 481.

Strielkowski, W., Gryshova, I. Y., \& Shcherbata, M. Y. (2017). Predatory publishing and Beall's list: lessons for the countries adapting novel research evaluation criteria. Наука і освіта, (8), 39-43.

Teixeira da Silva, J. A. T., \& Tsigaris, P. (2018). What value do journal whitelists and blacklists have in academia?. The Journal of Academic Librarianship, 44(6), 781-792.

Teixeira da Silva, J. A. (2020). An Alert to COVID-19 Literature in Predatory Publishing Venues. Journal of Academic Librarianship, 46(5): 102187.

Trencheva, T. S., \& Todorova, T. Y. (2014). Open access to scientific information: comparative study in DOAJ. Library Management, 35(4-5), 364-374.

Tsai, C. C., \& Lydia Wen, M. (2005). Research and trends in science education from 1998 to 2002: A content analysis of publication in selected journals. International journal of science education, 27(1), 3-14.

Vervoort, D., Ma, X., \& Shrime, M. G. (2020). Money down the drain: predatory publishing in the COVID-19 era. Canadian Journal of Public Health, 111(5), 665-666. 
Wager, E. (2017). Why we should worry less about predatory publishers and more about the quality of research and training at our academic institutions. Journal of epidemiology, 27(3), 87-88.

Wani, M. A., Agarwal, N., \& Bours, P. (2021). Impact of Unreliable Content on Social Media Users during COVID-19 and Stance Detection System. Electronics, 10(1), 5.

Warner, E. L., Waters, A. R., Cloyes, K. G., Ellington, L., \& Kirchhoff, A. C. (2021). Young adult cancer caregivers' exposure to cancer misinformation on social media. Cancer.

Watson, R. (2017). Beall's list of predatory open access journals: RIP. Nursing Open, 4(2). 
Peer

Review

\section{Online Supplement: Appendix}

Table 1A: Description of the Violations within Cabells' Predatory Reports

\begin{tabular}{|c|c|c|c|}
\hline Degree: & Severe & Moderate & Minor \\
\hline \multicolumn{4}{|c|}{$\begin{array}{l}\text { Infraction } \\
\text { Type }\end{array}$} \\
\hline Integrity & $\begin{array}{l}\text { - The same article appears in } \\
\text { more than one journal. } \\
\text { - Hijacked journal (defined as a } \\
\text { fraudulent website created to } \\
\text { look like a legitimate academic } \\
\text { journal for the purpose of } \\
\text { offering academics the } \\
\text { opportunity to rapidly publish } \\
\text { their research for a fee). } \\
\text { - Information received from the } \\
\text { journal does not match the } \\
\text { journal's website. } \\
\text { - The journal or publisher claims } \\
\text { to be a non-profit when it is } \\
\text { actually a for-profit company. } \\
\text { - The owner/Editor of the } \\
\text { journal or publisher falsely } \\
\text { claims academic positions or } \\
\text { qualifications. } \\
\text { - The journal is associated with } \\
\text { a conference that has been } \\
\text { identified as predatory. } \\
\text { - The journal gives a fake ISSN. }\end{array}$ & $\begin{array}{l}\text { - The title of the journal is } \\
\text { copied or so similar to } \\
\text { that of a legitimate } \\
\text { journal that it could cause } \\
\text { confusion between the } \\
\text { two. } \\
\text { - The name of the journal } \\
\text { references a country or } \\
\text { demographic that does } \\
\text { not relate to the content } \\
\text { or origin of the journal. } \\
\text { - The journal uses language } \\
\text { that suggests that it is } \\
\text { industry leading, but is in } \\
\text { fact a new journal. } \\
\text { - The journal/publisher } \\
\text { hides or obscures } \\
\text { relationships with for- } \\
\text { profit partner companies } \\
\text { that could result in } \\
\text { corporate manipulation of } \\
\text { science. }\end{array}$ & $\begin{array}{l}\text { - Insufficient resources are } \\
\text { spent on preventing and } \\
\text { eliminating author } \\
\text { misconduct that may result } \\
\text { in repeated cases of } \\
\text { plagiarism, self-plagiarism, } \\
\text { image manipulation, etc. (no } \\
\text { policies regarding } \\
\text { plagiarism, ethics, } \\
\text { misconduct, etc., no use of } \\
\text { plagiarism screens). } \\
\text { - The journal/publisher hides } \\
\text { or obscures information } \\
\text { regarding associated } \\
\text { publishing imprints or parent } \\
\text { companies. }\end{array}$ \\
\hline $\begin{array}{l}\text { Peer } \\
\text { Review }\end{array}$ & $\begin{array}{l}\text { - No editor or editorial board } \\
\text { listed on the journal's website } \\
\text { at all. } \\
\text { - Editors do not actually exist or } \\
\text { are deceased. } \\
\text { - The journal includes scholars } \\
\text { on an editorial board without } \\
\text { their knowledge or permission. } \\
\text { - Evident data that little to no } \\
\text { peer review is being done and } \\
\text { the journal claims to be "peer } \\
\text { reviewed." }\end{array}$ & $\begin{array}{l}\text { - The journal has a large } \\
\text { editorial board but very } \\
\text { few articles are published } \\
\text { per year. Inadequate peer } \\
\text { review (i.e., a single } \\
\text { reader reviews } \\
\text { submissions; peer } \\
\text { reviewers read papers } \\
\text { outside their field of } \\
\text { study; etc.). } \\
\text { - The journal's website } \\
\text { does not have a clearly } \\
\text { stated peer review policy. } \\
\text { - The founder of the } \\
\text { publishing company is } \\
\text { the editor of all of the } \\
\text { journals published by } \\
\text { said company. } \\
\text { - Evident data showing } \\
\text { that the editor/review } \\
\text { board members do not } \\
\text { possess academic } \\
\text { expertise to reasonably } \\
\text { qualify them to be }\end{array}$ & \\
\hline
\end{tabular}


Publication - The journal publishes papers Practices that are not academic at all, e.g. essays by laypeople or obvious pseudo-science.

- No articles are published or the archives are missing issues and/or articles.

- Falsely claims indexing in wellknown databases (especially SCOPUS, DOAJ, JCR, and Cabells).

- Falsely claims universities or other organizations as partners or sponsors. Machine-generated or other "sting" abstracts or papers are accepted. publication gatekeepers in the journal's field.

- No affiliations are given for editorial board members and/or editors.

- Little geographical diversity of board members and the journal claims to be International.

- The journal includes board members who are prominent researchers but exempt them from any contribution to the journal except the use of their names and/or photographs.

- Editorial board members (appointed over 2 years ago) have not heard from the journal at all since being appointed to the board.

- No copyediting. Little geographical diversity of authors and the journal claims to be International.

- The Editor publishes research in his own journal.

- The journal purposefully publishes controversial articles in the interest of boosting citation count.

- The journal publishes papers presented at conferences without additional peer review.

- The name of the publisher suggests that it is a society, academy, etc. when it is only a publisher and offers no real benefits to members.

- The name of the publisher suggests that it is a society, academy, etc. when it is only a solitary proprietary operation and does not meet the definition of the term used or implied non-profit mission.
- The number of articles published has increased by $25-49 \%$ in the last year. 
Fees - The journal offers options for researchers to prepay APCs for future articles.

- The journal states there is an APC or another fee but does not give information on the amount or gives conflicting information.

- The journal or publisher offers membership to receive discounts on APCs but does not give information on how to become a member and/or on the membership fees.

- The author must pay APC or publication fee before submitting the article (specifically calls the fee a publication fee, not a submission fee).

- The journal does not indicate that there are any fees associated with publication, review, submission, etc. but the author is charged a fee after submitting a manuscript.

- Surprise fees.

Indexing \&

- The journal uses misleading Metrics

Access \&

Copyright
- Authors are published several times in the same journal and/or issue.

- Similarly titled articles published by same author in more than one journal.

- The publisher displays prominent statements that promise rapid publication and/or unusually quick peer review (less than 4 weeks).

- The number of articles published has increased by $75 \%$ or more in the last year.

- The number of articles published has increased by $50-74 \%$ in the last year.

- The publisher or journal's website seems too focused on the payment of fees.
- The publisher or its journals are not listed in standard periodical directories or are not widely catalogued in library databases.
- States the journal is completely open access 
but not all articles are openly available.

- No way to access articles (no information on open access or how to subscribe).

- The journal is open access but no information is given about how the journal is supported financially (i.e. author fees, advertising, sponsorship, etc.).

- No policies for digital preservation.

- The journal has a poorly written copyright policy and/or transfer form that does not actually transfer copyright.

- The journal publishes not in accordance with their copyright or does not operate under a copyright license.

Business

- The journal has been asked to quit sending emails and has not stopped.

- The journal or publisher gives a business address in a Western country but the majority of authors are based in developing countries.

- Emailed solicitations for manuscripts from the journal are received by researchers who are clearly not in the field the journal covers.

- Email invitations for editorial board members or reviewers from the journal are received by researchers who are clearly not in the field the journal covers.

- Multiple emails received from a journal in a short amount of time.

- Emails received from a journal do not include the option to unsubscribe to future emails.
- No subscribers / nobody uses the journal. The journal's website does not allow web crawlers. 
Website

- The journal copyproofs and locks PDFs.
- The website does not identify a physical address for the publisher or gives a fake address.

- The journal or publisher uses a virtual office or other proxy business as its physical address.

- The website does not identify a physical editorial address for the journal.

- Dead links on the journal or publisher's website.

- Poor grammar and/or spelling on the journal or publisher's website.

- No way to contact the journal/only has web-form.

- The journal's website attempts to download a virus or malware.

Source: Compiled by the author from Cabells' website.

Table 2A: Codebook for the Website Content Analysis

\begin{tabular}{|c|c|}
\hline Code & Description \\
\hline COVID front & $\begin{array}{l}\text { Was anything about COVID-19 on the front-page of } \\
\text { the journal's website. }\end{array}$ \\
\hline Published this year & Has the journal published any articles in $2020 ?$ \\
\hline COVID Slow & $\begin{array}{l}\text { Did the journal include a warning that the peer review } \\
\text { process would be slow due to issues with the } \\
\text { pandemic? }\end{array}$ \\
\hline COVID CfP & $\begin{array}{l}\text { Did the journal issue a Call for Papers related to } \\
\text { COVID-19 }\end{array}$ \\
\hline Pub COVID & $\begin{array}{l}\text { Did the journal publish any articles related to the } \\
\text { pandemic? }\end{array}$ \\
\hline Other COVID & $\begin{array}{l}\text { Was there any other items on the journal's website that } \\
\text { mentioned COVID- } 19 \text { ? }\end{array}$ \\
\hline OC What & $\begin{array}{l}\text { If Other COVID is Yes, then describe the item/s that } \\
\text { was found. }\end{array}$ \\
\hline
\end{tabular}

Table 3A Cross-referenced Indexes of the Samples in the Research

\begin{tabular}{lllll}
\hline & Cabells' Predatory & Cabells' Journalytics & DOAJ & None \\
\hline Sample & 162 & 0 & 0 & 302 \\
DOAJ Sample & 0 & 251 & 28 & 0 \\
Discovered & 284 & 0 & 0 & 45 \\
\hline
\end{tabular}

Source: Compiled by the author from Cabells and DOAJ lists.

Note: Journals can appear on multiple lists. 